\title{
El Privilegio de Ótanes: la libertad del ciudadano en la Democracia Ateniense
}

\author{
Diego Alexander Olivera • \\ Centro de Estudios Comparados, \\ Universidad Nacional del Litoral - CONICET
}

\begin{abstract}
Resumen
Los especialistas en el mundo antiguo suelen recurrir, a la hora de definir la igualdad y la libertad del ciudadano en la democracia antigua, a la célebre definición ofrecida por Aristóteles en La Política. Pero la definición aristotélica presenta dos problemas. En primer lugar, resulta anacrónica cuando el objetivo es describir la noción de libertad ciudadana en el marco de la democracia radical del siglo $\mathrm{V}$, desde la reforma de Efialtes en 462 a.C. hasta la derrota a manos de Esparta en 404 a. C. Segundo, la definición propuesta por el estagirita apunta a cuestionar la democracia radical y el gobierno popular. Un enfoque comparativo permitirá demostrar que la definición aristotélica de la libertad del ciudadano no solo es ajena a la lógica que regula la participación ciudadana en el marco de la política asamblearia, sino que se muestra sumamente deficitaria para explicar esa lógica. En contraste, el testimonio de Heródoto en III, 80-83, en el llamado debate de los persas o de las formas constitucionales, insinúa una definición de la libertad del ciudadano que se ubica en el extremo opuesto de la que ofrece el estagirita, y se ajusta mucho más a las características que presenta la actuación del ciudadano en la asamblea democrática.
\end{abstract}

\section{Palabras clave:}

· Democracia · Aristóteles · Heródoto 


\begin{abstract}
When defining the equality and freedom of citizens in Ancient Times' democracy, scholars tend to resort to the famous definition coined by Aristotle in Politics. However, this definition presents two problems. First, it is anachronistic when the aim is to describe the notion of citizen freedom in the context of radical democracy of the 5th Century B.C. from Ephialtes' reform in 462 B.C. until the defeat of Sparta in 404 B.C. Second, the definition penned by the Greek philosopher is aimed at bringing into question radical democracy and popular government. A comparative approach will allow us to demonstrate that Aristotle's definition of citizen freedom not only is alien to the rationale that regulates citizen participation in the framework of the assembly's policy, but also that it is incapable of explaining such rationale. By contrast, Herodotus' testimony in III, 80-83 regarding the so called debate of the Persians or on the constitutional forms foreshadows a definition of citizen freedom which stands at the opposite end of the one offered by the Greek philosopher and is more attuned to the traits of the way in which citizens act in the democratic assembly.
\end{abstract}

\title{
Key words:
}

Democracy · Aristotle · Herodotus

La cuestión de la ciudadanía en la democracia antigua ha constituido recientemente el centro de un complejo debate sobre los «elementos modernos» de la ciudadanía clásica. ${ }^{1}$ En particular, la discusión gira en torno a la existencia de "cuasi derechos» en la democracia griega que puedan llegar a entenderse como similares a los derechos del individuo moderno. En el trasfondo de tal debate se halla el tema de la libertad del ciudadano, en uno y otro contexto, y su definición teórica. Aquí nos enfocaremos en este último punto; la definición teórica de la libertad del ciudadano en el contexto de la democracia ateniense del siglo V. Sobre lo primero, basta señalar que a diferencia de la democracia constitucional moderna, donde la igualdad se gana frente al poder del Estado, en la democracia antigua la igualdad es impuesta por una mayoría a una minoría. Como señalara Rancierè (1995:33) para los antiguos hay política cuando «la contingencia igualitaria irrumpe como libertad» del demos. 
Ahora bien, los especialistas suelen recurrir, a la hora de definir la igualdad y la libertad del ciudadano en la democracia antigua, a la célebre definición ofrecida por Aristóteles en La Política:

Una característica de la libertad es ser gobernado y gobernar por turno (eleutherías dè hèn mèn tò en mérei árkhesthai kaì árkhein). En efecto, la justicia, en la concepción democrática, consiste en tener igualdad según el número y no según el mérito. (Pol. 1317b, 2)

Pero la definición aristotélica presenta dos problemas. En primer lugar, resulta anacrónica cuando el objetivo es describir la noción de libertad ciudadana en el marco de la democracia radical del siglo V, desde la reforma de Efialtes en 462 a. C. hasta la derrota a manos de Esparta en 404 a. C. ${ }^{2}$ Segundo, como afirmó recientemente una comentarista del pensamiento aristotélico, la definición propuesta por el estagirita apunta a cuestionar la democracia radical que se caracterizaría según él por la negativa del demos a ser gobernado, y que por ende es incapaz de gobernar (Pechriggl, 2012:164).

Por tanto, es poco probable que la definición de Aristóteles se acerque a lo que el pensamiento democrático del siglo $\mathrm{V}$ percibía como la libertad de un ciudadano. De hecho, en el lenguaje del estagirita domina el termino arkhè, que se halla en la raíz de varios tipos de regímenes, como monarquía y oligarquía. Ober (2008:3-9) señala que a diferencia de esos regímenes, que se construyen dependiendo del número de individuos con acceso a las magistraturas de gobierno, la democracia no está construida en primera instancia por el número. ${ }^{3}$ La polarización entre democracia y oligarquía llevó al equívoco de entender a la primera como el régimen en que la mayoría ocupa los cargos y magistraturas, en oposición al segundo que se entendía como el control de las mismas por parte de la minoría. ${ }^{4}$

Así pues, la demokratía no supone solamente el acceso a las magistraturas por parte de una mayor cantidad de individuos, aunque éste podría ser un rasgo característico que la diferencia de oligarquía, sino que «es el régimen en el que el demos obtuvo una capacidad colectiva para lograr un cambio en el ámbito público» (Ober, 2008:7). El lugar donde se expresa esa capacidad colectiva es la asamblea, órgano principal del gobierno democrático.

Un enfoque comparativo permitirá demostrar que la definición aristotélica de la libertad del ciudadano no solo es ajena a la lógica que regula la participación ciudadana en el marco de la política asamblearia, sino que se muestra sumamente deficitaria para explicar esa lógica. En contraste, el testimonio de Heródoto en III, 80-83, en el llamado debate de los persas o de las formas constitucionales, insinúa una definición de la libertad del ciudadano que se ubica en el extremo opuesto de la que ofrece el estagirita, y se ajusta mucho más a las características que presenta la actuación del ciudadano en la asamblea democrática. La metodología comparativa nos permite entrecruzar los testimonios disímiles que las fuentes ofrecen sobre un mismo fenómeno y delimitar su temporalidad (Milia \& Lizarraga, 2011:31).

En ese sentido, lo que aquí se pretende es proponer la definición de Halicarnaso como alternativa de la aristotélica, por lo menos en lo que respecta a la democracia radical, y para eso se dividirá la exposición en dos partes. En la primera, se abordan las características de la asamblea como órgano de gobierno y espacio de configuración de la subjetividad política del ciudadano, en la segunda, se explicita la definición de la libertad del ciudadano que presenta Heródoto. 


\section{Todo el poder a la asamblea}

En el año 428 a. C. la ciudad de Mitilene en Lesbos, aliada de Atenas y parte de su imperio, decide abandonar la alianza y en consecuencia enfrenta una represalia por parte de la polis ática. Tras tomar la ciudad los atenienses deliberaron en asamblea sobre el castigo que correspondía a los Mitileneos. Según Tucídides aconteció lo siguiente:

Y deliberaron acerca de los prisioneros, y bajo los efectos de la indignación decidieron matar no solo a los allí presentes, sino también a todos los mitileneos adultos y vender como esclavos a niños y mujeres. (Th., III. 36)

Como resultado de la deliberación se envía ordenes al estratego Paquete para que haga cumplir la decisión del demos. Sin embargo, al día siguiente ciertos sectores del pueblo comienzan a mostrarse críticos hacía la decisión tomada en la asamblea anterior y exigen una nueva deliberación. Nuevamente los dos oradores que habían hablado el día anterior toman la palabra para defender una u otra perspectiva; Cleón en favor de matar a todos los miteleneos y Diódoto en favor de perdonarles la vida:

$\mathrm{Y}$ expuestas estas dos argumentaciones de forma tan equilibradamente contrapuesta entre si, los atenienses se vieron abocados a un conflicto de opiniones, y en la votación quedaron casi empatados, aunque la propuesta de Diódoto resultó vencedora. (Th., III. 49)

El ejemplo de Mitilene es uno de los pocos testimonios con que contamos sobre el funcionamiento de la asamblea democrática ateniense, y en él debemos observar la particularidad de que en un lapso de dos días el pueblo tomó dos decisiones completamente diferentes. Al parecer esto no sería una excepcionalidad circunscripta al episodio narrado por Tucídides, sino que sería una constante del comportamiento de la asamblea si atendemos al comentario de Aristófanes:

Y siendo calumniados por sus enemigos, ante los atenienses rápidos en tomar decisiones, con la imputación de burlarse de nuestra ciudad e insultar al pueblo en sus comedias. Solicita ahora mismo responder dirigiéndose a los atenienses rápidos en cambiar sus decisiones. (Ach. 630-32)

Así pues, la práctica asamblearia supone no solo la deliberación y la toma de decisión, que ha de hacerse sobre la marcha de los acontecimientos, sino también supone una capacidad de poner en cuestión dichas decisiones. Eso es lo que Castoriadis (1997) identificaba como el rasgo principal de una sociedad autónoma. Para Bauman (2007:145-146) el cenit de esa autonomía estaría marcada por el momento en que la asamblea encabeza sus decisiones con la formula "edoxe te boule kai to demo» (el consejo y el pueblo decretan). En efecto, las decisiones que toma la asamblea ateniense en el marco de la democracia radical tienen carácter de ley, y sólo pueden ser revocadas por otra asamblea, como bien demuestra el ejemplo de Mitilene. ${ }^{5}$

Raphael Sealey (2009:238-257) tiene una opinión distinta. Él considera que el dikasterion (tribunales) actuaba como un poder judicial autónomo de la asamblea con la finalidad de salvaguardar la libertad de los ciudadanos. Pero la noción de división de poderes y la concepción de la justicia como responsables de proteger las libertades civiles de los atropellos del Estado es una concepción moderna. En 
los tribunales atenienses actuaban los mismos ciudadanos que en la asamblea y eran elegidos por sorteo. ${ }^{6}$ Ninguno de los jueces era jurista profesional — como ninguno de los ciudadanos era político de profesión-, sino que eran jornaleros, tenderos, artesanos, etc. La ciudad, en tanto Estado, eran sus ciudadanos, y podía seguir existiendo incluso si eran expulsados de su territorio (Rhodes, 2009:61). ${ }^{7}$ Por lo tanto, los tribunales como el consejo son simplemente otros espacios de expresión de la comunidad en tanto colectivo de ciudadanos, como lo es la asamblea. ${ }^{8}$

Si los decretos de la asamblea son la ley y ningún poder es capaz de colocarse por arriba de la voluntad popular, se entiende la crítica de Aristóteles que ve en la democracia radical la existencia de un poder indefinido:

Y la multitud de esta índole está enteramente ociosa, pues el cuidado de las cosas privadas no los ata en absoluto, pero ata a los ricos, de modo que a menudo no toman parte de la asamblea ni del acto de juzgar. Por eso la multitud de los pobres llega a ser soberana del régimen político, pero no las leyes. (Pol., 1293²9

El problema, desde la crítica aristotélica, es que la asamblea no es una magistratura, más bien es «una arkhè que en rigor es un krátos» (Gallego, 2003:192). Lo que hace de ella un espacio de conflicto, de tensiones entre las partes. Pero también es un espacio sumamente igualitario donde la línea divisoria entre gobernantes y gobernados es inexistente (Meiksins Wood, 2011:49). Lo que no debe llevar a la suposición de que la polis clásica carecía de coacción, sino que la misma se ejercía por parte de la comunidad cívica a costa de esclavos y extranjeros (Paiaro, 2011: 223-242). Pero al interior de la comunidad, en el marco de la política asamblearia, los ciudadanos eran iguales entre sí y la coacción no tenía lugar, a menos que se estuviese dispuesto a sacrificar el carácter igualitario de la asamblea.

La peculiar organización igualitaria de la polis democrática ha motivado la recuperación, por parte de algunos especialistas, de los aportes teóricos del antropólogo francés Pierre Clastres. ${ }^{10}$ Desde dicho enfoque, la sociedad ateniense del siglo $\mathrm{V}$ puede ser entendida como una "comunidad indivisa», ${ }^{11}$ en tanto carece de un liderazgo escindido. La colectividad se piensa y se configura en el marco de la política asamblearia como un «nosotros». Los «líderes políticos» y los «demagogos» tenían una autoridad más bien frágil, y aunque podían disuadir al demos a votar alguna de sus propuestas, el gobierno recaía en la comunidad toda. ${ }^{12}$ Era ella quien «ejercía poder sobre los líderes y no viceversa» (Paiaro, 2014:133), ${ }^{13}$ por eso procuraba evitar la concentración de poder en manos de un individuo mediante dispositivos de seguridad como el «ostracismo» o la revisión de las acciones de los funcionarios públicos.

Así pues, la asamblea es el espacio donde la comunidad materializa el ideal de unidad que emana de su carácter indiviso. Más allá de las diferencias internas, toda decisión tomada por ella se expresa en nombre de la totalidad de los atenienses. El cuerpo de ciudadanos ha colocado el poder es meson, en el medio, de forma tal que nadie pueda apropiárselo (Vernant, 1965:65-81). De ese "colocar en el medio" surge la lógica igualitaria que ordena la política de la polis clásica. 


\section{Isonomía o la libertad del individuo en la democracia radical}

En el libro III de sus Historias Heródoto de Halicarnaso narra una escena que por inverosímil dice mucho del imaginario ateniense. Se trata de un supuesto episodio sucedido tras la muerte del mago Esmerdis, usurpador del trono persa después de la desaparición física del rey Cambises. En una habitación tres nobles persas debaten sobre qué hacer, una vez que la línea masculina del rey Ciro se ha extinto: continuar con el régimen monárquico o modificarlo. El trasfondo histórico del debate lo debemos buscar en Atenas en vísperas de las reformas de Clístenes. Allí, el Alcmeónida, Iságoras y los Pisistrátidas representarían cada una de las tres formas de gobierno (Cf. Asheri, 2007:472)..$^{14}$

En dicho debate, el noble Megabizo pronuncia un fuerte alegato a favor de la Oligarquía y en contra de la tiranía y el poder popular. Pero la oposición principal se da entre Ótanes, defensor de la «isonomía», y Darío que aboga por la continuidad monárquica. ${ }^{15}$ Ótanes identifica la democracia con el hecho de que «los magistrados se desempeñan por sorteo, cada uno rinde cuenta de su cargo y todas las deliberaciones se someten a la comunidad». ${ }^{16}$ La tiranía, en cambio, pervierte al mejor de los hombres, pues el problema no es el individuo sino el sistema. ${ }^{17}$ Finalmente, Darío alegará por la Monarquía, y en su discurso pone énfasis, al igual que Megabizo, en la inevitable realidad de que la democracia termina instituyendo la tiranía.

Como no podía ser de otra manera para el pensamiento helénico, dado que se trata de un debate entre bárbaros, termina por imponerse el argumento en favor de la Monarquía ${ }^{19}$. Pero lo interesante es lo que viene a continuación, pues Ótanes reclamó, según Heródoto, gozar de un llamativo privilegio:

«Camaradas, está bien claro que uno cualquiera de nosotros — bien sea que resulte designado por sorteo, que encomendemos su elección como tal a la totalidad de los persas, o que lo sea por cualquier otro procedimiento — ha de ser rey; sea como fuere, yo no voy a entrar en liza con vosotros, pues no quiero mandar, ni recibir órdenes. Renuncio pues al poder a condición de no estar, tanto yo, personalmente, como mis sucesivos descendientes, a las órdenes de ninguno de vosotros» (...). Y hoy en día la familia de Ótanes sigue siendo la única que, en Persia, goza de libertad y que, con tal de no conculcar las leyes de los persas, sólo obedece las órdenes que tiene a bien. (III., 83, 2-3)

El párrafo insinúa que Ótanes sería el único persa libre, a excepción del Gran Rey, porque es el único que no manda sobre otros y no se recibe órdenes de nadie. Entonces, ¿`se puede inferir que en Heródoto la libertad de un individuo pasa por no gobernar a otros y no ser gobernado? Ótanes renuncia al krátos, al poder que puede ser ejercido sobre otros, pero lo hace a condición de que los demás también renuncien a ejercerlo sobre él. ${ }^{18} \mathrm{~A}$ partir de ese momento Ótanes asume todo el krátos para sí mismo, es el único responsable de su devenir.

Pascal Payen (1997:193-203) otorga un exhaustivo análisis de los conceptos de krátos, arkhè y hegemoniè en Heródoto donde sostiene que "por lo tanto, krátos es una fuerza peligrosa que, ya que pone a un individuo por encima de otro, requiere 
ser controlado" (Payen, 1997:194), su presencia en la Historia se relaciona con los procesos de conquista, en estrecha vinculación con la arkhè. Krátos asegura el control de un territorio conquistado por los bárbaros, aparece como el momento de la victoria en circunstancias propias de la lucha. La arkhè se da por el ejercicio reiterado del Kratos, es un poder destinado a durar, y hegemonie aparece vinculado a arkhè en aquellos casos en que un pueblo logra imponerse sobre otro, y al obtener una superioridad temporal logra a través del ejercicio del krátos desplegar una arkhè: "Poder de una autoridad absoluta, como resultado de una guerra de conquista, la «hegemonía» es un legado temporal que el ejercicio de una superioridad (krátos) convierte en una dominación (arkhé) sostenible» (Payen 1997:196).

Ahora bien, ¿solo escapando a la Arkhè se obtiene la libertad? Eso explicaría la petición de Ótanes de no ser mandado y la situación particular del demos ateniense durante la Pentecontecia. Payen cree que para Heródoto existe la posibilidad de que Krátos cambie de valor y que efectivamente eso es lo que pasa con la instauración de la democracia, donde el poder es situado es meson, es decir en el medio y habilita la posibilidad de que la arkhè sea expulsada, pues en esa situación ningún individuo puede colocarse encima de otro, nadie manda, ni es mandado. A partir de entonces será la comunidad, percibida como un «nosotros», la que se instituya como única depositaria del poder expresado en la voluntad del demos.

El análisis de Payen permite observar que Heródoto, al asimilar isonomía con demokratía, inserta al régimen dentro de una tradición nobiliaria y aleja las críticas que identifican democracia con poder de los sectores populares. En la lectura del de Halicarnaso krátos ya no puede significar «superioridad» de una parte que domina sobre otra. Ha dejado de ser el signo de la división, para constituirse en la fuerza positiva que al ubicarse en el centro del ámbito público posibilita la igualdad.

La peculiar situación de Ótanes y el privilegio que goza conjuntamente con sus descendientes nos coloca frente a una definición de la libertad del ciudadano en el marco de la democracia diferente de la aristotélica. De hecho se puede profundizar aun más la vinculación entre el noble persa y la polis ática. En III, 141-150, con motivo de la restauración de la tiranía de Samos en la persona de Silosonte, hermano del fallecido Polícrates, Ótanes aparece otra vez en escena, pero esta vez, lo hace como comandante del ejército persa enviado por Darío a conquistar Samos. Entonces aparece mandando y siendo mandado, contradiciendo lo expresado en el debate de los persas ¿Por qué se da dicha contradicción? ¿Por qué el defensor de la isonomia democrática deviene en conquistador?

Para dilucidar semejante interrogante, es necesario pensar en Ótanes como una representación de Atenas en el sentido de ser «instrumento de un conocimiento mediato que hace ver un objeto ausente al sustituirlo por una «imagen» capaz de volverlo a la memoria» (Chartier, 1992:57-58), así la figura de Ótanes se asimila en el discurso a la polis ateniense, y construye para el receptor una referencia clara a ésta. Ótanes defiende la isonomia democrática, de la misma forma que lo haría un ateniense convencido de la eficacia de este régimen, no solo habla en griego, lo hace como un griego demócrata, y como Atenas es para Heródoto la expresión más acabada de la democracia, Ótanes habla como ateniense. ${ }^{19}$

Asimismo, la situación es similar a la de una Atenas que libre de tiranos al interior de su sociedad y en el exterior con su victoria sobre los persas, se encuentra en una posición hegemónica dentro de la liga de Délos que es un tanto contradictoria 
con los postulados democráticos (Placido, 1986:24). Según Balot (2009:54-68) la libertad no constituyó un valor central en la cultura aristocrática del período arcaico, sino que pasó a ocupar el centro del escenario tras los eventos de las guerras médicas. Propone vincular la libertad con los ideales masculinos de la andreía ateniense para explicar la agresividad de la política exterior durante el siglo V. Es posible que Balot acierte al identificar una relación entre la concepción de la libertad con la política imperial ateniense, pero es necesario precisarla.

$\mathrm{Al}$ interior de la comunidad cívica hay libertad e igualdad en tanto hay «ausencia» o «neutralización» del poder. Sin esa expulsión o negación de la división entre gobernantes y gobernados no puede existir el espacio común igualitario que supone el demos reunido en asamblea. Sin embargo, como colectivo, el demos domina sobre los «otros», esclavos y metecos, así como a las ciudades aliadas. ${ }^{20}$ De aquí se desprende otra concepción de libertad asociada a la capacidad de dominar o gobernar sobre los demás. Si entre ciudadanos la relación debe ser simétrica, entre ciudadanos y los «otros» la asimetría es tomada como natural. ${ }^{21}$

\section{Conclusión}

El empleo de un análisis comparativo en dos niveles —en el plano discursivo, comparando los distintos enunciados, y en el plano sociohistórico, comparando las diferentes realidades espacio-temporal en que se inscriben los enunciados- ha permitido identificar una variedad de concepciones y definiciones de la libertad en la Grecia Clásica. Esa variedad exige, por parte de los investigadores, cierta prudencia a la hora de optar por una u otra definición. En ese sentido, adquiere relevancia el contexto de producción de las obras y las experiencias sociopolíticas en que se ven insertos los autores.

En la perspectiva aristotélica las constituciones políticas se definen en relación a la parte que ejerce el gobierno de la polis, los pobres en la democracia, los ricos en la oligarquía y un individuo en la tiranía. La definición del ciudadano que él propone se ajusta a su idea de la politeia como régimen que hace compatible el criterio de libertad que rige en la democracia con el de propiedad que hace lo propio en la oligarquía. El ciudadano queda definido como aquel que participa en las instancias deliberativas representadas por la asamblea y los tribunales, pero queda excluido de las magistraturas las cuales deben ser reservadas a los ricos. Frente a la democracia radical donde el demos, es decir los sectores populares, gobierna sobre los ricos, el estagirita ofrece una definición donde «ambos criterios (libertad y propiedad) encuentran cabida en la constitución y ni los ricos ni los pobres se ven explotados por la otra parte de la polis» (López Barja, 2013:180).

La definición de Heródoto parte de la negación del conflicto, la comunidad sólo puede ser unidad. Por tanto, se centra en una idea de igualdad que hace inviable la dominación. En cambio Aristóteles considera al conflicto constitutivo de la política e inicia su reflexión desde la tesis de que las partes del cuerpo cívico están enfrentadas. ${ }^{22}$ La propuesta del estagirita apunta a crear consenso, la del de Halicarnaso a idealizar la democracia como eunomia, como el régimen capaz de superar la stasis. 


\section{Notas}

${ }^{1}$ Cf. Ober (2000:27-60), Olbrys \& Samaras (2007:111-141), Sancho Rocher (2011:243-266).

${ }^{2}$ Observa Sancho Rocher (1991:59-86): «En el tercer libro de la Política, el estagirita plantea la definición de ciudadano que, como es sabido, para él tiene un contenido político activo. Pero no hay que olvidar que Aristóteles representa sólo un ejemplo del esfuerzo, propio de su época, de reducir a un organigrama claro la realidad político social, frutos de siglos de evolución y que, por tanto, el resultado de su investigación no siempre es perfectamente aplicable a una situación concreta, ni mucho menos a cualquier época pasada».

${ }^{3}$ Monarquía (uno) Oligarquía (los pocos). En tanto, el término arkhè hace referencia a "cargos» «magistraturas», krátos, en la tradición homérica, supone el ejercicio de una "superioridad", "fuerza» o "poder». Cf. Benveniste (1983:280-287).

${ }^{4}$ Rancierè (1995) llama la atención sobre la doble acepción del término demos como el todo y la parte, la totalidad del cuerpo de ciudadanos y los sectores populares que son la mayoría de los ciudadanos. Sobre el origen peyorativo del término "democracia» entendida como el poder de los pobres, Cf. Carledge (2007: 155-169), también Loraux (2008: 251-272) que considera que el discurso democrático tendía a ocultar el krátos por una especie de negación del demos a admitir su victoria. Por su parte, Canfora (2014:158-162) se inclina por la idea de que es en la segunda mitad del siglo V, más precisamente en los años que van de la muerte de Pericles (429) hasta la tiranía de los Treinta (404), que el término democracia paso a significar «dominio» de los sectores populares. Hansen (2010:499-536) circunscribe a los textos historiográficos, filosóficos y panfletos políticos el uso del término con sentido de «sectores populares», en tanto que en los discursos de los oradores y en las fuentes epigráficas su sentido siempre es el de "totalidad» del cuerpo de ciudadanos.

${ }^{5}$ Cf. Gallego (2003:188), Canfora (1995:157).

${ }^{6}$ Barceló y Hernández de la Fuente (2014:192) llaman la atención sobre estos aspectos que diferencian las democracias antiguas y modernas.

${ }^{7}$ Cf. Hansen (1997:9-15) para quien polis es el término genérico para designar al Estado. Pero también designa la ciudad en tanto espacio físico y a la comunidad de polites.

8 «A partir de Efialtes, el Areópago solo ejercería funciones judiciales, mientras que la asamblea, el consejo y los tribunales realizarían de modo práctico los principios del poder popular» (Gallego, 2005:116-117). También Hansen (2010:499-536) señala que no hubo una separación adecuada de poderes entre los tribunales judiciales y la asamblea, aunque difieren en estructura y composición. Musti (2000:206-209) se inclina por una separación de poderes, sino acordada, al menos vinculada. Si bien un decreto de la asamblea podía ser objeto de una graphè paranómon, es factible que, como señala el propio Musti, sea en el siglo IV, cuando el centro de gravedad se desplaza de la asamblea a la dikastéria, el momento donde ese control de los tribunales sobre la asamblea podía llegar a 
realizarse. No obstante, Sealey yerra en atribuirle al tribunal popular un poder que lo asemeja al que tiene en las sociedades modernas el poder judicial como garante de las libertades civiles.

${ }^{9}$ El testimonio aristotélico además ilustra la diferencia entre ley y decreto y la importancia que tiene para los antiguos lo "promulgado" (ley) por sobre lo «votado» (decreto). En el hecho de que lo «votado» por la asamblea se coloque por encima de la ley es donde radica la distorsión democrática para el estagirita. En la democracia moderna, en cambio, lo votado (ley) es superior a lo promulgado (decreto). $\mathrm{Al}$ respecto $\mathrm{Cf}$. Musti (2000:213).

${ }^{10}$ Cf. Loraux (2007:243-264) Paiaro (2014:120-134) Gallego (2011b: 194-195).

${ }^{11}$ Clastres (2001: 202-203) lo expresa en los siguientes términos: «La comunidad primitiva es a la vez totalidad y unidad (...). Por esto el criterio de indivisión es fundamentalmente político: si el jefe salvaje carece de poder es porque la sociedad no acepta que el poder se separe de su ser, que se establezca una división entre el que manda y los que obedecen (...). La comunidad primitiva puede plantearse como totalidad porque se constituye en unidad: es un todo finito porque es un Nosotros indiviso». ${ }^{12}$ Ismard (2012:317-328) observa que en Atenas está ausente la idea de la polis como persona jurídica. En consecuencia, esa incapacidad de la ciudad para constituirse en persona jurídica independiente de la comunidad civil constituía un obstáculo para la formulación, en términos legales, de la noción de representación.

${ }^{13}$ Vale recordar que el Viejo Oligarca en su constitución de los atenienses 1.8, dice: «el pueblo no quiere ser esclavo, aunque la polis sea bien gobernada, sino ser libre y mandar».

${ }_{14}$ Para Hartog (2003:302), desde un punto de vista cultural, Ótanes habla en griego, mientras Darío lo hace en persa. Asheri (2007:472) también llama la atención sobre los diferentes estilos de ambos discursos. ${ }^{15}$ En verdad Ótanes utiliza el término isonomía, pero la descripción que hace de la misma es obviamente la del régimen democrático.

${ }^{16}$ III. 80, 3-4: «Es más, si accediera a ese poder, hasta lograría desviar de sus habituales principios al mejor hombre del mundo, ya que, debido a la prosperidad de que goza, en su corazón cobra aliento la soberbia; y la envidia es connatural al hombre desde su origen».

${ }^{17}$ Aunque solo sea en el plano histórico, pues como ha observado Canfora (1995:162) en el plano dialéctico el debate no ha tenido vencedor, en tanto, que el pensamiento político griego reconoce el carácter cíclico de las constituciones.

${ }^{18}$ Sin embargo, Ótanes no hace uso del término cuando describe la isonomía en III., 80. 6: «Una multitud que gobierna (plêthos árkhon)... desempeña los cargos (arkhàs árkhei) por sorteo y ejerce un poder (arkhén) sometido a rendición de cuentas». Sí lo hace Megabizo en su crítica al régimen en III., 81.1 "Otorgar el poder (to krátos) a la multitud». Según Gallego (2011a:162), «Lo que el debate permite percibir es una fluctuación en el uso del lenguaje de la hegemonía entre el ejercicio de la arkhè conforme al número del agente (plêthos, oligarquía) y el ejercicio 
del krátos según la calidad del agente (dêmos, áristoi), que puede o no coincidir con el anterior.»

${ }^{19}$ Lo que no quiere decir que Heródoto sea demócrata.

${ }^{20}$ Buis (2015:27-61) señala que en las relaciones inter-póleis existe una tensión entre «the language of equality (as an analogical projection of internal isonomía) and hegemonic intention». Payen (2012:92-101) cree que krátos (superioridad, dominación) es la fuerza que regula las relaciones entre póleis y que, por tanto, los acuerdos entre las ciudades no son vinculantes. De la misma opinión es Ekstein (2006:37-78).

${ }^{21}$ Aristóteles entiende la dominación como justificable cuando se da entre quienes son desiguales por naturaleza pero injusta cuando las partes son esencialmente iguales.

${ }^{22}$ Tesis que ejerció cierta influencia en el concepto de lo político que propone Carl Schmitt, como señaló recientemente López Barja (2013:171-182).

\section{Referencias bibliográficas}

Aristóteles (1988). Política (Traducción de Manuela García Valdés). Madrid: Gredos.

(1995). La constitución de los atenienses (Traducción Alberto Bernabe). Madrid: Abada

Asheri, D. (2007). Book III. En Murray, O. \& Moreno, A. (Eds.), $A$ Commentary on Herodotus Books I-IV (pp. 379-528). Oxford: Oxford University Press.

BaLot, R. (2009). The Freedom to Rule: Athenian Imperialism and Democratic Masculinity. En Tabachnick, D. \& Koivukoski, T. (Eds.), Enduring Empire: Ancient Lesson for Global Politics (pp. 54-68). Toronto: Toronto University Press.

Barceló, P. y Hernández de la Fuente, J. (2014). El pensamiento politico griego: teoría y praxis. Madrid: Trota editorial.

Benveniste, E. (1983). Vocabulario de las instituciones indoeuropeas. Madrid: Taurus.

Buis, E. (2015). Between Isonomía and Hegemonía: Political Complexities of Transitional Justice in Ancient Greece. En Bersgmo, M. et al. (Ed.), Historical Origins of International Criminal Law: Vol. 3 (pp. 27-61). Bruselas: Torkel Opsahl Academic Epublisher.

Canfora, L. (1995). El Ciudadano. En Vernnt, J. P. (Ed.) El Hombre Griego (pp. 141-164). Madrid: Alianza Editorial.

(2014) El mundo de Atenas. Barcelona: Anagrama.

Carledge, P. (2007). Democracy, Origins of: Contribution to Debate. En Raaflaub, K. et al. (Eds.), Origins of Democracy in Ancient Greece (pp. 155-169). Berkeley-Los Angeles-Londres: University of California Press. Chartier, R. (1992). El mundo como representación. Barcelona: Gedisa. Clastres, P. (2001). Investigaciones en antropología politica. Barcelona: Gedisa. 
Eкstein, A. (2006). Mediterranean Anarchy, Interstate war, and rise of Rome. Berkeley-Los Angeles-Londres: University of California Press. GALlego, J. (2003). Democracia en tiempos de tragedia: asamblea ateniense y subjetividad política. Buenos Aires: Miño y Dávila.

(2005). Campesinos en la ciudad. Bases agrarias de la infantería hoplita. Buenos Aires: Editorial del Signo.

(2011a). Atenas, entre el Krátos y la Arkhè: el lenguaje de la de hegemonía y el agotamiento de la democracia. En Cortés Copete, J. M. et al. (Comps.) Grecia ante los Imperios: V reunión de historiadores del mundo griego (pp. 155-166). Sevilla: Secretaría de publicaciones Universidad de Sevilla.

(2011b). La asamblea ateniense y el problema del estado. Instauración y agotamiento de una subjetividad política. En Campagno, M. et al. (Comps.) El Estado en el mediterráneo antiguo (pp. 181-222). Buenos Aires: Miño y Dávila.

Hansen, M. (1997). ПO $\Lambda \mathrm{I} \Sigma$ as the generic term for state. En Nilssen (ed.) Yet more studies in the ancient Greek polis (pp. 9-15). Stuttgart: Hiztoria Eriszelschntten 117.

(2010). The concepts to Demos, Ekklesia and Dikasterion in Classical Athens. Greek, Roman and Byzantine Studies, 50, 499-536.

Hartog, F. (2003). El espejo de Heródoto. Buenos Aires: Fondo Cultura Económica.

Heródoto (1995). Historias (Traducción de Carlos Schrader). Madrid: Gredos.

López Barja, P. (2013). Conflicto versus consenso. De Ciceron a Aristóteles pasando por Carl Schmitt. En Cid López, R. \& García Fernández, E. (Comp.), Debita Verba: Estudios en homenaje al profesor Julio Mangas. Vol. 1 (pp. 171-182).

Loraux, N. (2007). Notas sobre el Uno, el dos y lo múltiple. En Abensour, M. (Comps.) El espiritu de las leyes salvajes (pp. 243-260). Buenos Aires: ediciones del sol.

(2008a). La Guerra Civil en Atenas. La politica entre la sombra y la utopía. Madrid: Akal.

(2008b) La ciudad dividida. El olvido en la memoria de Atenas.

Buenos Aires: Katz editores.

Meirsins Wood, E. (2011). De Ciudadanos a Señores Feudales. Buenos Aires: Paidós.

Milia, L. \& LizÁrraga, C. (2011). La problemática de la comparación en la historia. El hilo de la fábula, 9, 13-34.

OвеR, J. (2000). Quasi Rights: Participatory Citizanship and Negative Liberties in Democratic Athens. Social Philosophy and Policy Foundation, 17, 27-60 .

- (2008). The original Meaning of «Democracy»: Capacity to Do Things, not Majority Rule. Constellation, 15 (1), 3-9.

Olbrys, K. \& Samaras, Th. (2007). Is Ancient Democracy Quasi-liberal. RIDA, 54, 111-141.

Paiaro, D. (2011). Las ambigüedades del Estado en la democracia ate- 
niense. En Campagno, M. et al. (Comps), El Estado en el mediterráneo antiguo (pp. 223-242). Buenos Aires: Miño y Dávila. ( - (2014). Salvajes en la ciudad clásica. Pierre Clastres y la antropología política de la democracia ateniense. En Campagno, M. (Ed.) Pierre Clastres y las sociedades antiguas (pp. 119-142). Buenos Aires : Miño y Dávila.

Payen, P. (1997). Les iles nomades: Conquérir et résister dans l'enquête d'Hérodote. Paris: Editions E.H.E.S.S.

(2012) Le revers de la guerre en Grèce ancienne. Paris: Belin.

Pechriggl, A. (2012). ÁRKHEIN KAÌ ÁRKHESTHAI En las Políticas de Aristóteles. En Sancho Rocher, L. et al. (Comps). Lógos y Arkhé: Discurso politico y autoridad en la Grecia Antigua. Buenos Aires: Miño y Dávila.

Placido, D. (1986). De Heródoto a Tucídides. Gerion, 4, 17-46. Madrid: Universidad Complutense de Madrid.

Rancierè, J. (1995). El desacuerdo. Política y filosofía. Buenos Aires: Nueva Visión.

Rhodes, P. (2009). Civic Ideology and Citizenship. En Balot, R. (Ed.), A Companion to Greek and Roman Political Thought (pp. 57-69). Oxford: Wiley-Blackwell.

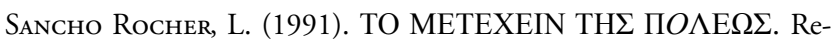
flexiones acerca de las condiciones de pertenencia ciudadana entre Solon y Pericles. Gerion, 9, 59-86. Madrid: Universidad Complutense de Madrid.

(2011). Comunidad e individuo en la democracia Antigua: Garantías del individuo y espacio privado en la democracia ateniense. En Campagno, M. et al. (Comps.), El Estado en el mediterráneo antiguo (pp. 243-266). Buenos Aires: Miño y Dávila.

SeALey, R. (2009). Democratic Theory and Practice. En Salmons II, L. (Ed.), The Cambridge Companion to the Age of Pericles (pp. 238-257). Cambridge: Cambridge University Press.

Tucídides. (2000) Historia de la guerra del Peloponeso (Traducción de Antonio Guzmán Guerra). Madrid: Alianza.

Vernant, J.P. (1965). Los origenes del pensamiento griego. Buenos Aires: Eudeba.

\section{Olivera, Diego Alexander}

«El Privilegio de Ótanes: la libertad del ciudadano

Fecha de recepción: $12 \cdot 10 \cdot 15$ en la Democracia Ateniense». El hilo de la fábula. Fecha de aceptación: $15 \cdot 11 \cdot 15$ Revista anual del Centro de Estudios Comparados (16), 159-171. 
